Supplement Issue 1: International Tehran Breast Cancer Congress (TBCC9)

\title{
Expression of NAV2 Correlated with Change of Tumor Size in Breast Cancer Patients
}

\author{
Solmaz Kholdi ${ }^{1,}$, Mohammad Reza Kholdi i ${ }^{1}$, Abolfazl Rad ${ }^{2}$, \\ Mohammad Mahdi Forghani Fard ${ }^{1}$ \\ ${ }^{1}$ Department of Biology, Damghan Branch, Islamic Azad University, Damghan, Iran \\ ${ }^{2}$ Cellular and Molecular Research Center, Sabzevar University of Medical Sciences, \\ Sabzevar, Iran \\ ${ }^{*}$ Corresponding Author: Solmaz Kholdi, Department of Biology, Damghan Branch, \\ Islamic Azad University, Damghan, Iran, E-mail: Solmazkholdi@yahoo.com
} DOI: $10.21859 / \mathrm{mci}$-supp-45

\section{Keywords:}

Breast Cancer

NAV2

Tumor Size

\begin{abstract}
Introduction Breast cancer is the first leading cause of cancer death among Iranian women and the second worldwide. This type of cancer is histologically malignant and in case of invasion, cancer cells are found in lymph nodes. Despite its high rate of incidence, the molecular biology of this cancer is still unknown. Our aim was to study the expression NAV2, which located on chromosome 11(11p15.1), as members of Navigator neurons gene family, in breast cancer.

Materials and Methods: In this study, total RNA was extracted from 40 tumor and 40 normal tissues using RNA extraction kit. After cDNA synthesis with Takara cDNA synthesis kit, expressional analysis NAV2 gene was evaluated by Real time PCR techniques. Using SPSS, we analyzed different clinopatholigical data with expression of NAV2 in breast cancer patients.

Results: NAV2 was decreased $47.5 \%$ in tumor samples compared to normal samples .Statistical analysis showed that correlation was observed between NAV2 gene expression and change tumor size in breast cancer. This means that decreased expression of this gene causes to increase tumor size and also in risk of grade disease with high level. It can be concluded that these genes may be affective tumor genesis and progression of breast cancer.

Conclusions: Decreasing the expression of NAV2 end in increases the size of the tumor, increases the stage and also severity of the disease.
\end{abstract}

